OPEN ACCESS

Edited by:

Zhanping You,

Michigan Technological University,

United States

Reviewed by:

Tao Ma,

Southeast University, China

Ning Guo,

Southwest University, China

*Correspondence:

lixi@csust.edu.cn

Specialty section:

This article was submitted to

Structural Materials,

a section of the journal

Frontiers in Materials

Received: 06 August 2021 Accepted: 07 September 2021

Published: 17 September 2021

Citation:

Qian G, Yang H, Li X, Yu H, Gong Xand Zhou H (2021) A Unified Strength Model of Asphalt Mixture Considering

Temperature Effect.

Front. Mater. 8:754187.

doi: 10.3389/fmats.2021.754187

\section{A Unified Strength Model of Asphalt Mixture Considering Temperature Effect}

\author{
Guoping Qian ${ }^{1,2}$, Hui Yang ${ }^{1}$, Xi Li ${ }^{1 *}$, Huanan Yu ${ }^{1}$, Xiangbing Gong ${ }^{1}$ and Hongyu Zhou ${ }^{1}$ \\ ${ }^{1}$ School of Traffic and Transportation Engineering, Changsha University of Science and Technology, Changsha, China, ${ }^{2}$ National \\ Engineering Laboratory for Highway Maintenance Technology, Changsha University of Science and Technology, Changsha, \\ China
}

The strength characteristics of asphalt mixture is crucial for the design and construction of asphalt roads. A strength model considering the effect of temperature is presented in this paper based on unified strength theory (UST). Firstly, direct tensile tests, uniaxial compression tests and anti-shear property tests of asphalt mixture were carried out respectively at different temperatures. Key mechanical parameters were obtained, including tensile strength $\left(\sigma_{t}\right)$, compressive strength $\left(\sigma_{\mathrm{c}}\right)$ and shear strength $\left(\tau_{0}\right)$ at different temperatures. Besides, the temperature sensitivity of $\sigma_{\mathrm{t}}, \sigma_{\mathrm{c}}$ and $\tau_{0}$ was systematically analyzed. The results showed that the UST parameters of tensilecompression strength ratio $\alpha$ and failure criterion parameter $b$ have a linear relationship with temperature $t$. A theoretical model to describe strength characteristics with the temperature of asphalt mixture was developed finally. The developed model was validated via applicability analysis. and it will provide theoretical support for the study of strength characteristics of asphalt mixture and engineering practice.

Keywords: asphalt mixture, strength model, temperature, direct tensile tests, uniaxial compression tests, anti-shear property tests

\section{INTRODUCTION}

The asphalt pavement is the most widely used high grade pavement in road construction at present. The strength characteristics of asphalt mixture have long been the core issue of asphalt pavement research (Provis, 2015; Wang et al., 2020; Pugno et al., 2021). However, the mechanical properties of the asphalt mixture are complex. It is mechanical viscous, elastic, plastic and temperature-sensitive, which has brought great challenges to establish an accurate strength model. The classical strength model of Tresca and Mole-Colume have been widely adopted in the construction of asphalt pavement nowadays due to their simple form and clear physical meaning (Xu, 1994; Xue, 1997; $\mathrm{Yu}, 2002$; Niu et al., 2014). However, they ignored the effect of intermediate principal stress $\sigma_{2}$ on the asphalt mixture strength, leading to insufficient estimation of the true strength of asphalt pavement and the inconsistency between the design of asphalt mixture pavement structure and the practical application (Guan et al., 2014; Yang et al., 2015).

To establish an accurate theoretical model to describe the effect of intermediate principal stress on asphalt mixture strength. Some scholars explored and achieved important results under the unified strength model framework (Suo et al., 2011; Yu et al., 2011; Xia et al., 2019). Suo et al. (2015) conducted orthogonal tests and confirmed the influence of the second principal stress, loading rate and temperature on the strength of asphalt mixture. Yang et al. (2015) introduced a failure criterion 
TABLE 1 | Test results of SBS (I-D) modified asphalt.

\begin{tabular}{lccr}
\hline Project & Result & Requirements & Method \\
\hline Penetration $\left(25^{\circ} \mathrm{C}, 100 \mathrm{~g}, 5 \mathrm{~g}\right), 0.1 \mathrm{~mm}$ & 56 & $30-60$ & T0604-2011 \\
Ductility $\left(5^{\circ} \mathrm{C}, 5 \mathrm{~cm} / \mathrm{min}\right), \mathrm{cm}$ & 34 & $\geq 20$ & T0605-2011 \\
Softening point $(\mathrm{R} \& \mathrm{~B}),{ }^{\circ} \mathrm{C}$ & 79 & $\geq 60$ & $\mathrm{~T}$ \\
kinematic viscosity $\left(135^{\circ} \mathrm{C}\right)$, Pa s & 2.31 & $\leq 3$ & $\mathrm{~T}$ \\
Thin film oven mass loss, $\%$ & 0.1 & $\leq \pm 1.0$ & T0619-2011 \\
\end{tabular}

TABLE 2 | Aggregate density.

Seive size $(\mathrm{mm})$

Density $\left(\mathrm{g} / \mathrm{cm}^{3}\right)$

$\begin{array}{lll}13.2 & 9.5 & 4.75\end{array}$

$2.730 \quad 2.729$

\subsection{6}

2.715

\subsection{8}

2.716

0.6
2.717

2.717

0.3

2.717
0.15

2.718

\subsection{5}

2.719
Mineral powder 2.753 of asphalt pavement considering the influence of tensioncompression strength ratio of asphalt mixture and intermediate principal stress. The criterion confirmed that the tension-compression strength ratio had a significant influence on pavement stress and its distribution, and the pavement stress level would be significantly increased after considering intermediate principal stress. Xia et al. (2019) established a unified strength model of asphalt mixture under different loading modes by using the relationship between strength ratio and loading rate indirect tensile test, unconfined compression test and indirect tensile test. This model solves the uncertainty of strength performance of asphalt mixture under different loading models.

The applicability of the UST under specific temperature conditions of asphalt mixture has been verified (Suo et al., 2015). However, asphalt is a typical temperature-sensitive material, and few strength models can consider both intermediate principal stress and temperature. Therefore, the temperature is still the key problem that restricts the development of asphalt mixture strength theory.

This paper is based on the UST. The direct tensile test, uniaxial compression test and anti-shear property test of asphalt mixture are conducted under five temperature conditions. The tensile strength $\sigma_{\mathrm{t}}$, compressive strength $\sigma_{\mathrm{c}}$ and shear strength $\tau_{0}$ were used as the indexes. The influence of the stress component on the strength of asphalt mixture at different temperatures was analyzed. The variation of $\sigma_{\mathrm{t}}, \sigma_{\mathfrak{c}}$, and $\tau_{0}$ at different temperatures were obtained. A unified strength model of asphalt mixture which can consider the influence of intermediate principal stress and temperature effect was established.

\section{MATERIALS AND SPECIMEN PREPARATION}

\section{Materials}

In this research, the SBS (I-D) modified asphalt was used. The conventional test of the SBS (I-D) was performed following the JTG E20-2011, (2011), and the results were shown in Table 1. Table 1 indicates that all performance indexes meet the Technical Specification for Highway Asphalt Pavement (JTG F40-2004, 2004).
The aggregate is basalt produced in Nanjing, China. The mineral powder is ground from basalt. The AC-13C dense graded asphalt mixture is adopted, and the aggregate grading is determined according to the JTG F40-2004 (2004). The aggregate density of each file is shown in Table 2, and the gradation curve is provided in Figure 1.

The optimum asphalt content (OAC) is determined by the Marshall test method combined with practical experience of asphalt pavement, and the optimum OAC is $5.3 \%$. The Marshall test results are shown in Table 3.

\section{Test Methods}

Material Test System-810 (MTS-810) was adopted as the loading equipment. The system has the advantages of simple structure and convenient operation, which can be used for ordinary tests and fatigue tests of various materials such as stretching, compression and bending under different temperature environments. The size of the specimen is a cylinder with a diameter of $100 \mathrm{~mm}$ and a height of $100 \mathrm{~mm}$, which is formed by the static pressure method. To comprehensively analyze the strength characteristics of the asphalt mixture, the specimen was insulated by the testing machine environmental insulation box. The temperature precision is $\pm 0.5^{\circ} \mathrm{C}$. Then three sets of parallel tests of direct tensile, uniaxial compression and anti-shear property test at different temperatures were studied. Finally, the arithmetic mean value was taken as the experimental value.

\section{Direct Tensile Strength Test}

To analyze the influence of temperature on the tensile resistance of asphalt mixture, direct tensile tests were conducted on three groups of prefabricated specimens at $5,15,20,40$ and $60^{\circ} \mathrm{C}$, respectively. The size of the specimen is a cylinder with a diameter of $100 \mathrm{~mm}$ and a height of $100 \mathrm{~mm}$. The stretching rate was $1 \mathrm{~mm} / \mathrm{min}$. To avoid the eccentric tension of the specimen during the test, the concentric circles with fine lines were prepared during the drawing plate forming to ensure that the specimen could be accurately centered during the adhesive process. On the other hand, ball valves are used at both ends of the drawing board to connect the loading shaft of the MTS testing machine (Huang et al., 2019). According to the measured average maximum load, the tensile strength can be calculated as follows: 


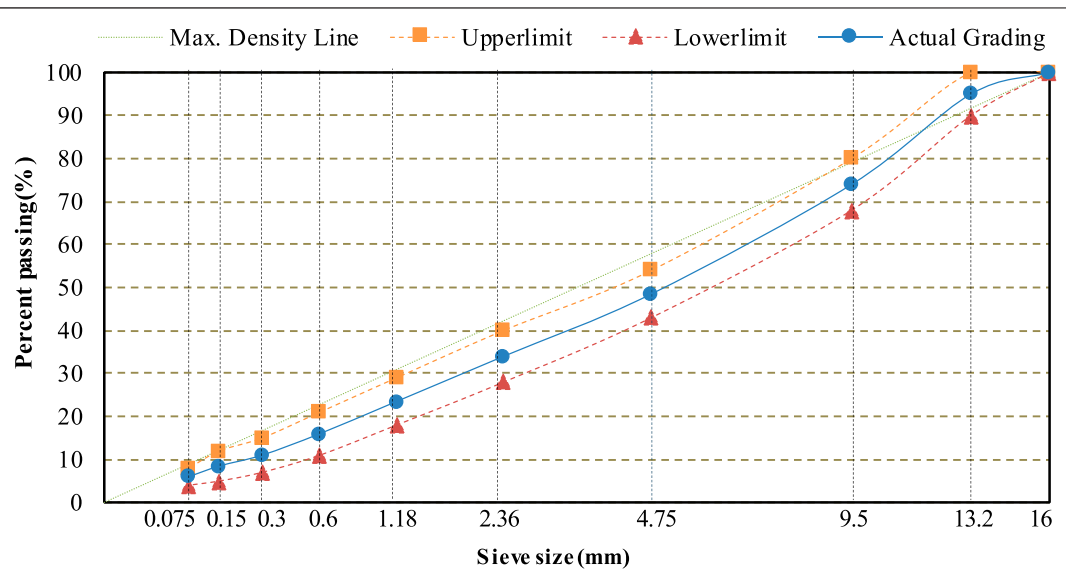

FIGURE 1 | Design grading envelope of $A C-13 C$ asphalt mixture.

TABLE 3 | Marshall test results.

\begin{tabular}{|c|c|c|c|c|c|c|c|}
\hline Oil-stone ratio (\%) & $\gamma_{\mathrm{t}}\left(\mathrm{g} / \mathrm{cm}^{3}\right)$ & $\gamma_{\mathrm{f}}\left(\mathrm{g} / \mathrm{cm}^{3}\right)$ & $\mathbf{V}(\%)$ & VFA (\%) & VMA (\%) & Stability (KN) & Flow value $(0.1 \mathrm{~mm})$ \\
\hline 8 & 2.605 & 2.407 & 7.6 & 56.1 & 17.3 & 14.8 & 20.1 \\
\hline 5.1 & 2.594 & 2.414 & 6.9 & 60.1 & 17.3 & 16.6 & 25.5 \\
\hline 5.4 & 2.582 & 2.459 & 4.8 & 70.0 & 16.0 & 15.7 & 28.9 \\
\hline 5.9 & 2.565 & 2.471 & 3.5 & 78.0 & 15.9 & 16.5 & 32.5 \\
\hline 6.4 & 2.544 & 2.496 & 2.0 & 87.1 & 15.5 & 15.4 & 38.7 \\
\hline Technology index & - & - & $4-6$ & $65-75$ & $>14.8$ & $>8$ & $15-40$ \\
\hline
\end{tabular}

${ }^{a} \gamma_{t}$ is maximum theoretical relative density, $\gamma_{f}$ is relative density of bulk volume, W is Void Volume, VFA is Voids Filled with Asphalt, VFA is Voids in Mineral Aggregate.

$$
\sigma_{t}=\frac{4 P}{\pi d^{2}}
$$

where $\sigma_{\mathrm{t}}$ is the tensile strength of the specimen, with the unite in $\mathrm{MPa} . P$ is the maximum load of specimen failure, with the unite in $N$. $d$ is the diameter of the specimen, with the unite in $\mathrm{mm}$.

\section{Uniaxial Compression Test}

To obtain the compressive strength characteristics of asphalt mixture at different temperatures. Three sets of prefabricated specimens were held at temperatures of $5,15,20,40$ and $60^{\circ} \mathrm{C}$ respectively. Uniaxial compression tests with a loading rate of $2 \mathrm{~mm} / \mathrm{min}$ were carried out. The size of the specimen is a cylinder with a diameter of $100 \mathrm{~mm}$ and a height of $100 \mathrm{~mm}$. The compressive strength could be obtained according to the average maximum load measured:

$$
\sigma_{c}=\frac{4 P}{\pi d^{2}}
$$

where $\sigma_{\mathrm{c}}$ is the tensile strength of the specimen, with the unite in $\mathrm{MPa} . P$ is the maximum load of specimen failure, with the unite in $N$. $\mathrm{d}$ is the diameter of the specimen, with the unite in $\mathrm{mm}$.

\section{Anti-Shear Property Test}

Triaxial shear test, coaxial shear test and uniaxial penetration test are commonly used to test the shear performance of asphalt mixture (Bi and Sun, 2005; Feng et al., 2008; Zhang and Li, 2012; Xie and Wang, 2019). The uniaxial penetration test is to apply

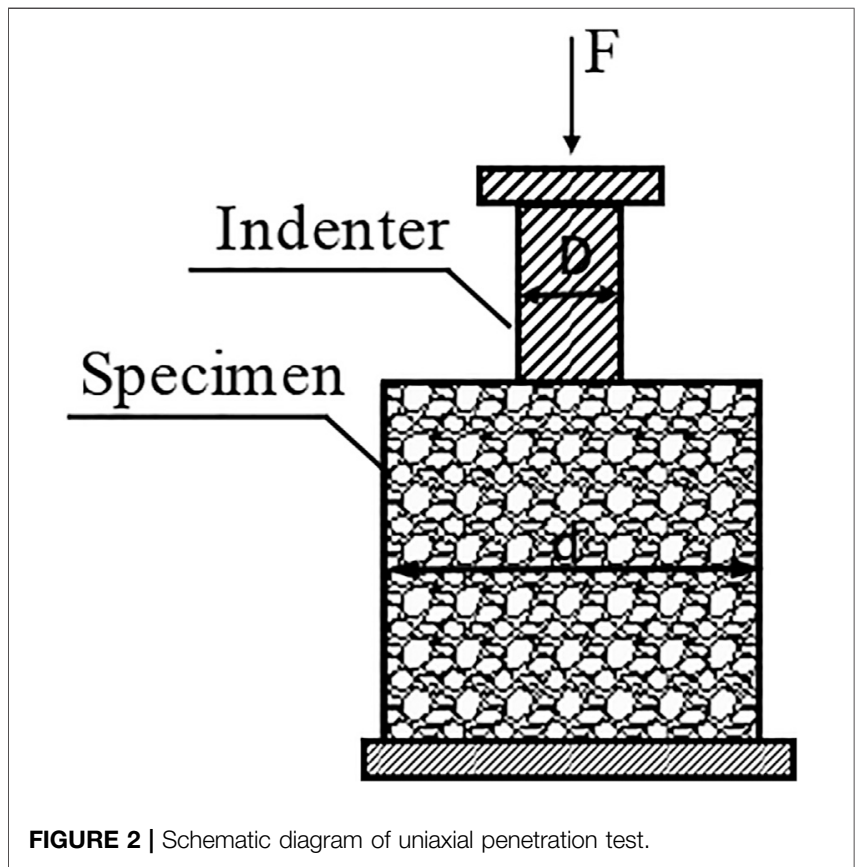

pressure on the specimen with the penetration head, and measure the stress and strain of the pressure head, then calculate the shear strength of the specimen through Eq. 3. The product of the maximum penetration pressure obtained from the test and 


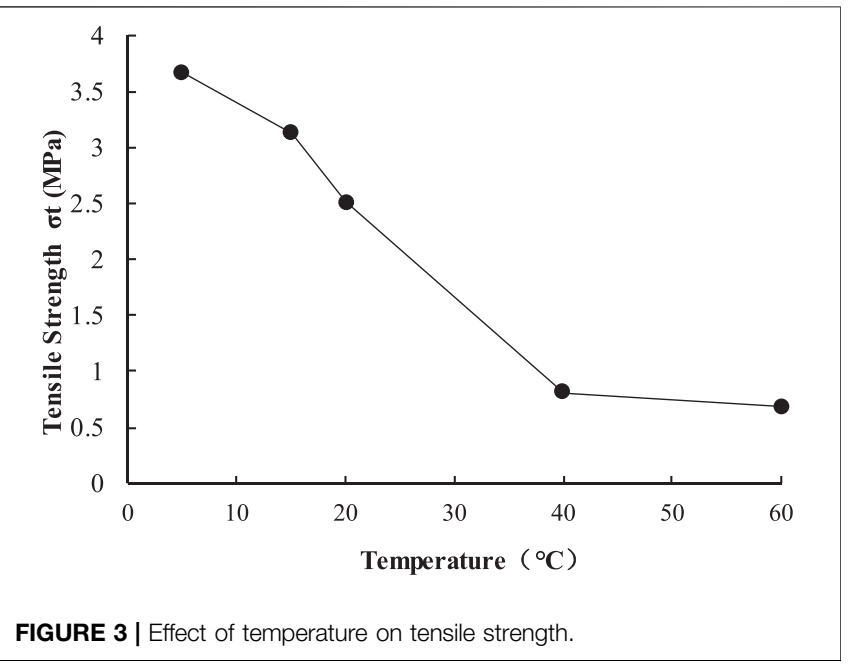

the strength parameter is the maximum shear stress $\tau_{\max }$ of the asphalt mixture specimen (Kou et al., 2020):

$$
\tau_{\max }=C \times P
$$

where $C$ is the strength parameter when the penetration intensity is $1 \mathrm{MPa}$ and Poisson's ratio is $0.35 . P$ is the penetration pressure.

The uniaxial penetration test is easy to operate, the equipment is simple, and the stress mode of the specimen is consistent with the pavement. It can effectively evaluate the anti-shear property of asphalt mixture (Kou et al., 2020). Therefore, a uniaxial penetration test is adopted to test the anti-shear property of asphalt mixture in this study at different temperatures. Specifically, uniaxial penetration tests were carried out at temperatures of $5,15,20,40$ and $60^{\circ} \mathrm{C}$, respectively. The size of the specimen is a cylinder with a diameter of $100 \mathrm{~mm}$ and a height of $100 \mathrm{~mm}$. The steel indenter diameter was $28.5 \mathrm{~mm}$ and the loading rate was $1 \mathrm{~mm} / \mathrm{s}$. The diagrammatic sketch of the uniaxial penetration test is shown in Figure 2.

\section{STATIC STRENGTH CHARACTERISTICS OF ASPHALT MIXTURE AT DIFFERENT TEMPERATURES}

\section{Direct Tensile Strength Test Results}

The ultimate tensile failure test results of asphalt mixture at different temperatures are shown in Figure 3.

As can be seen from the Figure 3, the tensile performance of AC-13(SBS) asphalt mixture decreases monotonically with the increase of testing temperature at temperatures of $5,15,20,40$, and $60^{\circ} \mathrm{C}$. The inflection point of the relationship between the tensile strength and temperature appears at about $40^{\circ} \mathrm{C}$. The strength changes significantly in the range of $5-40^{\circ} \mathrm{C}$, and the value of the tensile strength changes $2.866 \mathrm{MPa}$, which belongs to the temperature-sensitive area. In the range of $40-60^{\circ} \mathrm{C}$, the value of the tensile strength changes only $0.119 \mathrm{MPa}$, which belongs to the temperature-insensitive area. It is worth noting that, although the asphalt mixture has tensile high strength when the

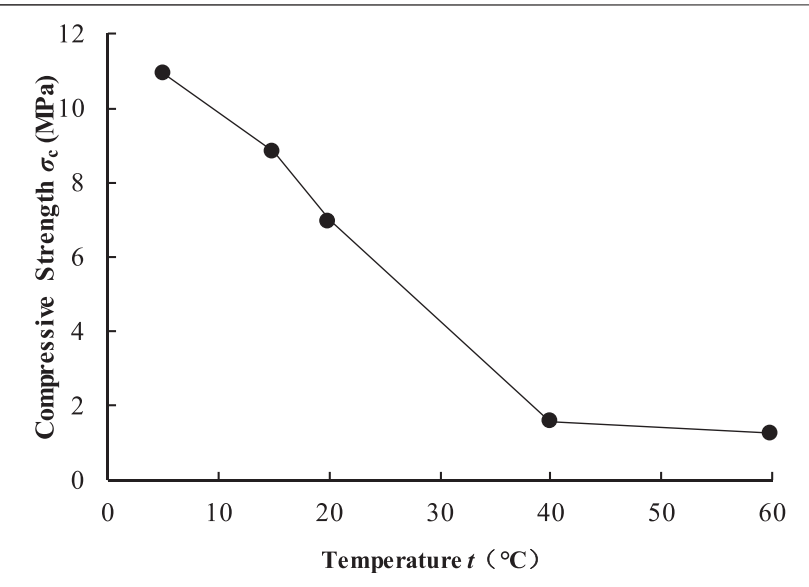

FIGURE 4 | Effect of temperature on compressive strength.

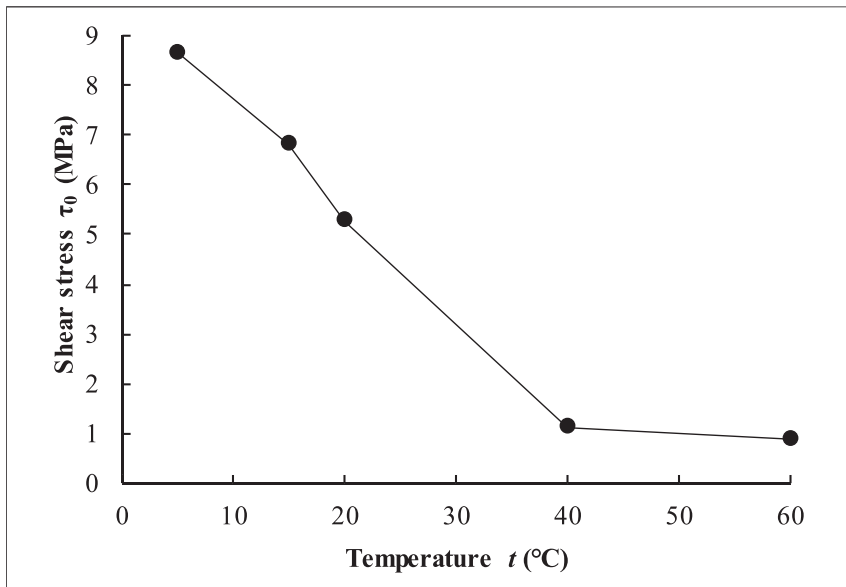

FIGURE 5 | Effect of temperature on shear performance.

temperature is relatively low, the strength index is more sensitive to temperature. Therefore, the reasonable tensile strength index needs to consider the influence of temperature.

\section{Uniaxial Compression Test Results}

The ultimate compressive test results of asphalt mixture at different temperatures are presented in Figure 4.

It can be seen from the Figure 4 that at temperatures of 5, 15, 20,40 , and $60^{\circ} \mathrm{C}$, the compressive performance of AC-13(SBS) asphalt mixture decreases monotonically with the increase of testing temperature. Especially in the range of $20-40^{\circ} \mathrm{C}$, the compressive strength changes significantly with the temperature, and the amplitude decreased is $9.347 \mathrm{MPa}$. When the temperature rises from 40 to $60^{\circ} \mathrm{C}$, the compression strength of the asphalt mixture decreases, with a value change of only $0.119 \mathrm{MPa}$. The inflection point of compressive strength is still $40^{\circ} \mathrm{C}$. In addition, the asphalt mixture has high strength when the temperature is relatively low, but the temperature sensitivity of the strength index is large. Therefore, the reasonable compressive strength index needs to consider the effect of temperature. 


\section{Anti-Shear Property Test Results}

Combined with the unconfined compressive strength test results of the asphalt mixture mentioned above. The uniaxial penetration test results of specimens are shown in Figure 5.

According to the Figure 5, the shear performance decreases monotonically with the increase of temperature. The inflection point occurs when the temperature drops to $40^{\circ} \mathrm{C}$. In the range of $5-40^{\circ} \mathrm{C}$, the change of shear strength is particularly significant, and the shear strength decreases linearly with temperature. For each increase in temperature, the strength decreases by about $0.22 \mathrm{MPa}$. When the temperature exceeds $40^{\circ} \mathrm{C}$, the overall shear strength of the asphalt mixture is low, and the strength decreases with the further increase of temperature.

Because of the temperature sensitivity of asphalt, the tensile, compressive and shear properties of asphalt mixture show obvious temperature dependence. For AC-13(SBS) asphalt mixture used in this test, the change of strength with temperature has obvious stages. The inflection point of the strength change with temperature is $40^{\circ} \mathrm{C}$. In the range of $5-40^{\circ} \mathrm{C}$, the strength decreases rapidly with temperature, and the relationship between them is linear. In the range of $40-60^{\circ} \mathrm{C}$, the overall strength of the mixture continues to decrease with temperature, but the rate of decrease is small.

Furthermore, the temperature sensitivity of the tensile strength, compressive strength and shear strength of asphalt mixture are different. Concretely speaking, the sensitivity of compressive strength is the largest, followed by the sensitivity of shear strength, and the sensitivity of tensile strength is the least. This is because, with the increase of temperature, the rheological properties of asphalt materials increase and the tensile properties decrease. At the same time, with the increase of temperature, the bonding between asphalt and aggregate increases. Based on the above test results, the quantitative relationship between temperature and strength of asphalt mixture is further analyzed.

\section{UNIFIED STRENGTH MODEL OF ASPHALT MIXTURE CONSIDERING TEMPERATURE}

UST can consider the influence of three principal stresses $\sigma_{1}, \sigma_{2}$, and $\sigma_{3}$ on the material strength, and can explain the interval of the effect of intermediate principal stresses. It has been widely applied to describe the strength characteristics of a material. The suitability of UST for asphalt mixtures has been verified. However, it has mostly been carried out at specific temperatures (Suo et al., 2015; Yang et al., 2015; Xia et al., 2019). Considering the objectivity of temperature sensitivity of asphalt material, this section attempts to establish a unified strength model of asphalt mixture considering the temperature effect. Firstly, the basic theory of unified strength is introduced, and then the strength model is established based on the strength parameters obtained under different temperatures and loading conditions.

\section{Unified Strength Theory}

UST is a set of yield criterion and failure criterion, which was first proposed and developed by Yu (1992), Yu (1994), Yu (2018). The three principal stresses are expressed as follows (Yu et al., 2011):

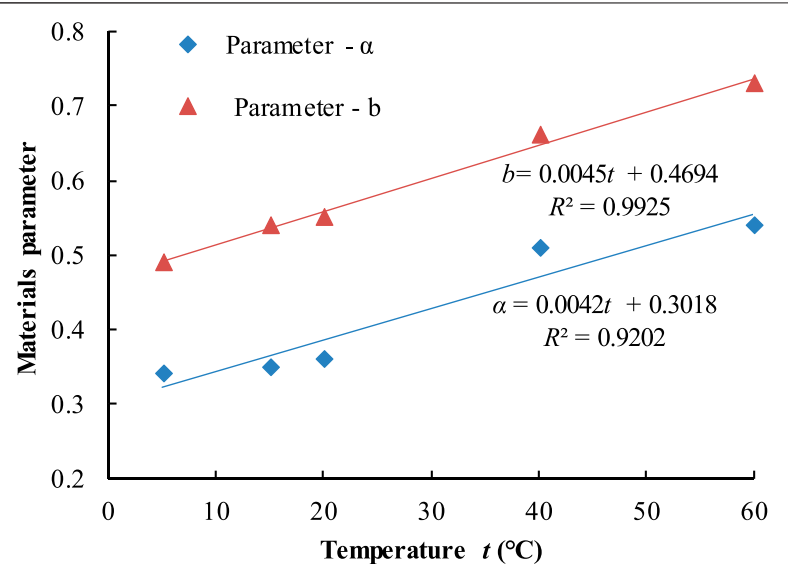

FIGURE $6 \mid \alpha$ and $b$ values and fitting curves at different temperatures.

$$
\begin{gathered}
\text { when } \sigma_{2} \leq \frac{\sigma_{1}+\boldsymbol{\alpha} \sigma_{3}}{1+\boldsymbol{\alpha}}, F=\sigma_{1}-\frac{\boldsymbol{\alpha}}{1+\boldsymbol{b}}\left(\boldsymbol{b} \sigma_{2}+\boldsymbol{\sigma}_{3}\right)=\sigma_{\boldsymbol{t}} \\
\text { when } \boldsymbol{\sigma}_{2} \geq \frac{\sigma_{1}+\boldsymbol{\alpha} \boldsymbol{\sigma}_{3}}{1+\boldsymbol{\alpha}}, \boldsymbol{F}=\frac{1}{1+\boldsymbol{b}}\left(\sigma_{1}+\boldsymbol{b} \sigma_{2}\right)-\boldsymbol{\alpha} \boldsymbol{\sigma}_{3}=\sigma_{\boldsymbol{t}}
\end{gathered}
$$

where $\alpha$ is the coefficient of tensile-compression characteristics of the material, reflecting the tensile-compression strength ratio of the material; $b$ is the failure criterion parameter, which reflects the influence of the intermediate principal shear stress and the normal stress on the corresponding plane on the material failure.

The expressions of failure criterion parameter $b$ and tensioncompression characteristic coefficient $\alpha$ are respectively (Suo et al., 2015):

$$
\begin{gathered}
\boldsymbol{b}=\frac{(1+\boldsymbol{\alpha}) \tau_{0}-\boldsymbol{\sigma}_{t}}{\boldsymbol{\sigma}_{t}-\tau_{0}} \\
\boldsymbol{\alpha}=\frac{\boldsymbol{\sigma}_{t}}{\boldsymbol{\sigma}_{\boldsymbol{c}}}
\end{gathered}
$$

where $\sigma_{\mathrm{t}}$ is the uniaxial tensile strength, MPa. $\tau_{0}$ is the shear strength of the material, $\mathrm{MPa} . \sigma_{\mathrm{c}}$ is the uniaxial compressive strength, MPa.

UST has been widely used in cement concrete, rock and soil materials (Kolupaev et al., 2013; Guan et al., 2018; Yu, 2018; Deng et al., 2020). Lijun et al. (Suo et al., 2015) confirmed that the second principal stress, test temperature and loading rate have effects on the strength of asphalt mixture, but the exact influence law does not get. Chengdong et al. (Xia et al., 2019) analyzed the relationship between strength ratio and loading rate, and established a unified strength model of asphalt mixture under different loading modes.

\section{Uniform Strength Criteria for Asphalt Mixtures Considering Temperature}

The measured test parameters $\sigma_{\mathrm{t}}, \sigma_{\mathrm{c}}$, and $\tau_{0}$ are substituted into Eqs 4, 5. The UST parameters $\alpha$ and $b$ of asphalt mixture at different temperatures can be obtained. The results and fitting curves are shown in Figure 6.

It can be seen from Figure 6 that with the increase of temperature, the tension-compression ratio $\alpha$ and the failure 


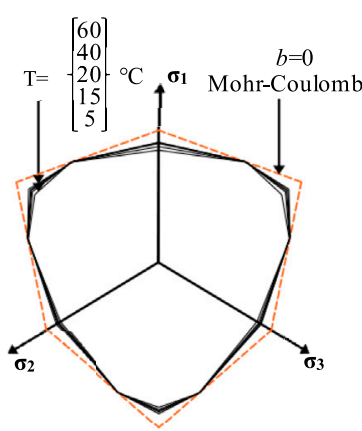

$\mathrm{T}=5 \sim 60^{\circ} \mathrm{C}$

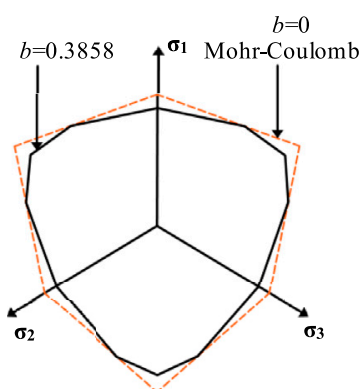

$\mathrm{T}=20^{\circ} \mathrm{C}$

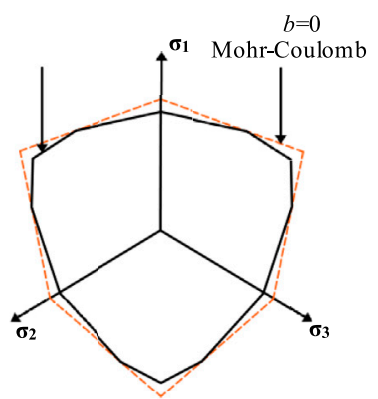

$\mathrm{T}=5^{\circ} \mathrm{C}$

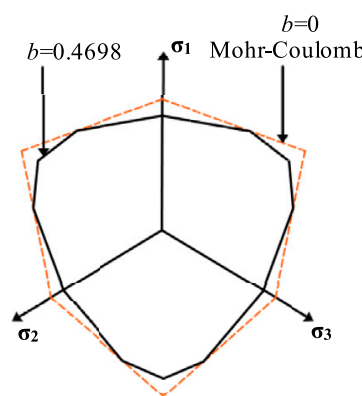

$\mathrm{T}=40^{\circ} \mathrm{C}$

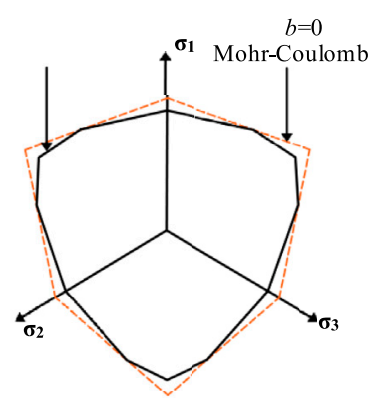

$\mathrm{T}=15^{\circ} \mathrm{C}$

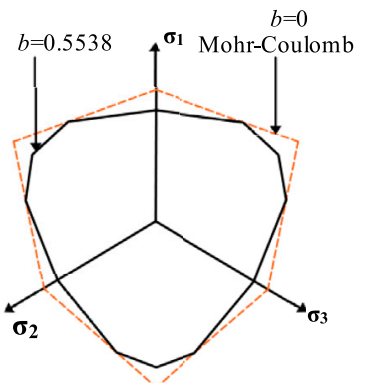

$\mathrm{T}=60^{\circ} \mathrm{C}$

FIGURE 7 | Partial plane limit trace diagram of UST at different temperatures.

criterion parameter $b$ increase. It shows that compared with tensile properties, the increase of temperature makes the compressive properties of the mixture decrease more greatly, and the difference between tensile strength and shear strength of the mixture decreases. The tension-pressure ratio $\alpha$ and the failure criterion parameter $b$ showed an obvious positive linear correlation with temperature, which could be expressed by Eqs 6, 7 .

$$
\begin{aligned}
& \alpha=0.0045 t+0.4694 \\
& b=0.0042 t+0.3018
\end{aligned}
$$

where $t$ is the temperature of asphalt mixture.

By substituting Eqs 8, 9 into Eqs 2, 3, the asphalt mixture UST considering temperature effect can be obtained. The expression is as follows:

$$
\begin{aligned}
& \text { when } \sigma_{2} \leq \frac{\sigma_{1}+\boldsymbol{\alpha} \sigma_{3}}{1+\alpha} \\
& \qquad F=\sigma_{1}-\frac{0.0045 t+0.4694}{0.0042 t+1.3018}\left[(0.0042 t+0.3018) \sigma_{2}+\sigma_{3}\right]=\sigma_{t}
\end{aligned}
$$

when $\sigma_{2} \geq \frac{\sigma_{1}+\boldsymbol{\alpha} \sigma_{3}}{1+\boldsymbol{\alpha}}$

$$
\begin{aligned}
\boldsymbol{F}= & \frac{1}{0.0042 \boldsymbol{t}+1.3018}\left[\boldsymbol{\sigma}_{1}+(0.0042 \boldsymbol{t}+0.3018) \boldsymbol{\sigma}_{2}\right. \\
& \left.-(0.0045 \boldsymbol{t}+0.4694) \boldsymbol{\sigma}_{3}\right]=\boldsymbol{\sigma}_{\boldsymbol{t}}
\end{aligned}
$$

According to Eqs 8, 9, the limit traces of the deviatoric plane of UST at different temperatures is shown in Figure 7. The UST yield surface of asphalt mixture considering temperature and intermediate principal stress effect is shown in Figure 8.

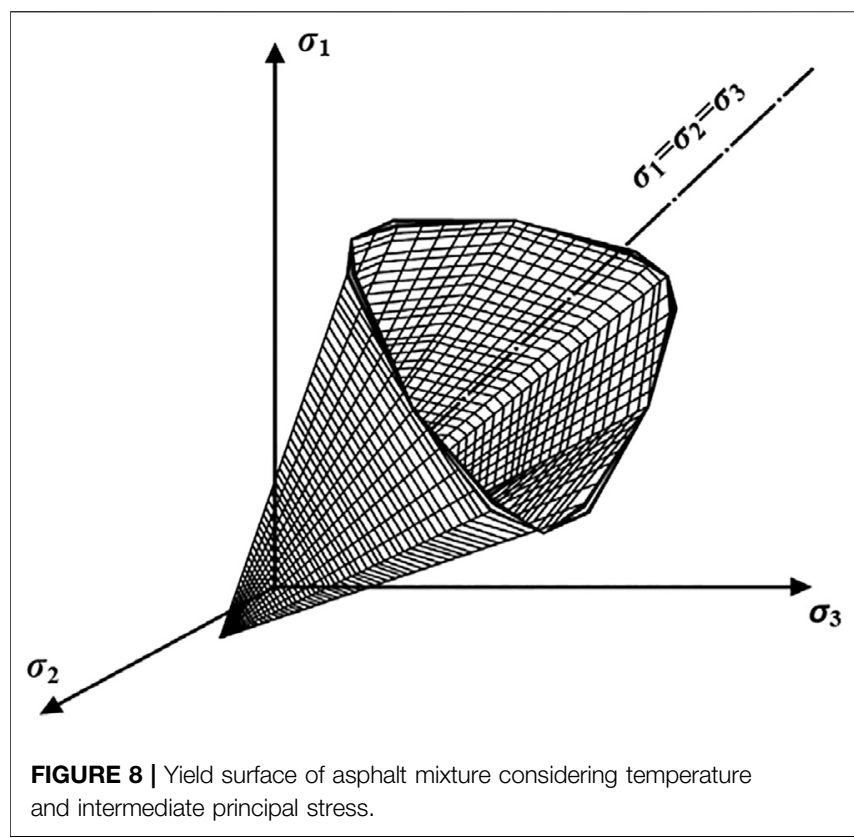

Figures 7, 8 display that the deviant plane limit trace decreases with the increase of temperature. The strength of the material decreases gradually under the condition of complex stress. The tension-pressure ratio $\alpha$ and failure criterion parameter $b$ change with temperature, so that the strength of the asphalt mixture shows different forms: 
When the parameter $b=1$, the model is simplified to the double shear stress strength theory. Its physical meaning is as follows: when the two large principal shear stresses and the corresponding normal stress function on the unit body reach a certain limit value, the material will be destroyed. The mathematical expression is:

$$
\begin{gathered}
\text { when } \sigma_{2} \leq \frac{\sigma_{1}+1.2175 \sigma_{3}}{2.2175}, F=\sigma_{1}-0.6088\left(\sigma_{2}+\sigma_{3}\right)=\sigma_{t} \\
\text { when } \sigma_{2} \geq \frac{\sigma_{1}+1.2175 \sigma_{3}}{2.2175}, F=\frac{1}{2}\left(\sigma_{1}+\sigma_{2}\right)-1.2175 \sigma_{3}=\sigma_{t}
\end{gathered}
$$

when $b=0$, the model is simplified into Mohr-Coulomb strength theory, and its mathematical expression is as follows:

$$
\sigma_{1}-\frac{\sigma_{1}}{\sigma_{c}} \sigma_{3}=\sigma_{1}-0.1460 \sigma_{3}=\sigma_{t}
$$

when $b \in(0,1)$, the strength theory of partial plane limit trace dodecagon.

A unified strength model of asphalt mixture considering temperature effect is established in this paper. This model can not only reflect the effect of intermediate principal stress $\sigma_{2}$ on material yield, but also its two expressions can reflect the change of stress state characteristics when the intermediate principal stress $\sigma_{2}$ increases from $\sigma_{2}=\sigma_{3}$ to $\sigma_{2}=\sigma_{1}$. That is, the transition from the generalized tensile stress state $\sigma_{2} \leq \frac{\sigma_{1}+\alpha \sigma_{3}}{1+\alpha}$ to the generalized compressive stress state $\sigma_{2} \geq \frac{\sigma_{1}+\alpha \sigma_{3}}{1+\alpha}$. In other words, when the intermediate principal stress $\sigma_{2}$ increases from near the minimum principal stress $\sigma_{3}$ to the maximum principal stress $\sigma_{1}$, the strength of the asphalt mixture gradually increases, and then decreases from the peak value after the strength reaches the peak value. The model improves the calculation accuracy of asphalt mixture strength at different temperatures, and provides a UST criterion based on temperature effect for the failure characteristics analysis of asphalt mixture. It can provide a more powerful design basis for the strength design of asphalt pavement at different temperatures.

\section{CONCLUSION}

In this paper, UST was introduced into the asphalt mixture. Through the direct tensile test, uniaxial compression test and anti-shear test of asphalt mixture, the strength characteristics of asphalt mixture under various temperatures were analyzed. The asphalt mixture UST considering the effect of temperature is presented. The specific conclusions are as follows:

1. With the increase of temperature, the tensile, compressive and shear properties of the asphalt mixture decrease monotonically. The inflection point is around $40^{\circ} \mathrm{C}$. In the range of $5-40^{\circ} \mathrm{C}$, the temperature sensitivity of the asphalt mixture is larger and decreases linearly. When the temperature exceeds $40^{\circ} \mathrm{C}$, the temperature sensitivity of the strength decreases, but the overall strength is also small.
2. The temperature sensitivity of tensile, compressive and shear properties of asphalt mixture is different. Among them, the compressive strength sensitivity is the largest, followed by the shear strength sensitivity, and the tensile strength sensitivity is the smallest.

3. The asphalt mixture UST considering the temperature effect is established. The model can consider the influence of three principal stresses and temperature on the strength of the asphalt mixture. As the value of model parameter $b$ changes, it can degenerate into the classical strength theory.

4. The strength model of asphalt mixture considering temperature established in this paper extends the traditional UST. This is conducive to the further improvement of the strength theory of asphalt pavement. However, it has not been verified in actual engineering, and further research can be carried out in this direction.

\section{DATA AVAILABILITY STATEMENT}

The original contributions presented in the study are included in the article/supplementary material, further inquiries can be directed to the corresponding author.

\section{AUTHOR CONTRIBUTIONS}

GQ provided the ideas and guided the entire experiment. HY and XL conducted experiments and data analysis, and completed the manuscript. HY directed data analysis, manuscript writing and checking. XG and HZ contributed to the writing, translation and verification of the manuscript. All authors have read and agreed to the published version of the manuscript.

\section{FUNDING}

The research was supported by the National Key R\&D Program of China (grant number: 2018YFB1600100); and the Special Funds for the Construction of Innovative Provinces in Hunan, China (grant number: 2019SK2171); and the Science and Technology Innovation Program of Hunan Province (grant number: 2020RC4048); and the Excellent Youth Project of Hunan Providence Department of Education (grant number: 19B030); the National Science Foundation of Hunan Project in Hunan Province, China (2020JJ5576).

\section{ACKNOWLEDGMENTS}

We would like to thank all our enthusiastic colleagues, editors and reviewers who provided guidance and advice on this article. 


\section{REFERENCES}

Bi, Y. F., and Sun, L. J. (2005). Research on Test Method of Asphalt Mixture's Shearing Properties. J. Tongji Univ. 8, 1036-1040. doi:10.3321/j.issn:0253374X.2005.08.009

Deng, L., Fan, W., Chang, Y., Zhang, S., and Liu, S. (2020). Determination and Influence of the Unified Strength Theory Parameter for Loess. Environ. Earth Sci. 79, 445. doi:10.1007/s12665-020-09208-8

Feng, J. L., Guo, Z. Y., Yang, Q., and Xu, S. G. (2008). Study on Co-axial Shear Test Method of Asphalt Mixes. J. Tongji Univ. 10, 1395-1398. doi:10.3321/j.issn: 0253-374X.2008.10.01610.1016/j.solidstatesciences.2008.01.004

Guan, H.-x., Wang, H.-q., Liu, H., Yan, J.-j., and Lin, M. (2018). The Effect of Intermediate Principal Stress on Compressive Strength of Different Cement Content of Cement-Stabilized Macadam and Different Gradation of AC-13 Mixture. Appl. Sci. 8, 2000. doi:10.3390/app8102000

Guan, H. X., Li, L. Y., Yang, H. Y., Liu, H., and Luo, Z. J. (2014). Intermediate Principal Stress Effect on Asphalt Mixture at Low Temperature. China J. Highw. Transport 11, 11-16. doi:10.12733/jics20102815

Huang, T., Qi, S., Jiang, H. H., Huang, M. Y., Li, M., and Li, Y. P. (2019). Stress and Stiffness Characteristics of Asphalt Mixture under Uniaxial Tensile Stress State. J. Cent. South Univ. 2, 460-465. doi:10.11817/ j.issn.1672-7207.2019.02.027

JTG E20-2011 (2011). Standard Test Methods of Bitumen and Bituminous Mixtures for Highway Engineering. Beijing: Ministry of Transport of the People's Republic of China.

JTG F40-2004 (2004). Tehnical Specifications for Construction of Highway Asphalt Pavements. Beijing: Ministry of Transport of the People's Republic of China.

Kolupaev, V. A., Yu, M.-H., and Altenbach, H. (2013). Visualization of the Unified Strength Theory. Arch. Appl. Mech. 83, 1061-1085. doi:10.1007/s00419-0130735-8

Kou, C., Pan, X., Xiao, P., Kang, A., and Wu, Z. (2020). Shear Deformation Behavior of a Double-Layer Asphalt Mixture Based on the Virtual Simulation of a Uniaxial Penetration Test. Materials 13, 3700. doi:10.3390/ma13173700

Niu, J., Liu, G. L., Tian, J., Zhang, Y. X., and Meng, L. P. (2014). Comparison of Yield Strength Theories with Experimental Results. Eng. Mech. 1, 181-187. doi:10.6052/j.issn.1000-4750.2012.09.0622

Provis, J. L. (2015). Grand Challenges in Structural Materials. Front. Mater. 2. doi:10.3389/fmats.2015.00031

Pugno, N. M., Provis, J. L., Dai, L., Pegoretti, A., Cannillo, V., Li, W., et al. (2021). Editorial: Covid-19: Materials Science and Engineering Challenges. Front. Mater. 8, 708684. doi:10.3389/fmats.2021.708684

Suo, L. J., Tong, H. F., and Wang, B. G. (2011). Influence of Intermediate Principal Stress on Asphalt Mixture Strength in Positive Temperature. J. Chang'an Univ. 4, 12-1521. doi:10.19721/j.cnki.1671-8879.2011.04.003

Suo, L. J., Wang, B. G., and Zheng, C. C. (2015). Experiment on Strength of Asphalt Mixture Based on Second Principal Stress. J. Zhengzhou Univ. 1, 79-82. doi:10.3969/j.issn.1671-6833.2015.01.019
Wang, G., Wang, X., Yan, Z., Qin, L., and Gao, Z. (2020). Analysis of the Influence of Temperature Field on the Dynamic Modulus of Rubber Asphalt Pavement. Front. Mater. 7, 586457. doi:10.3389/fmats.2020.586457

Xia, C., Lv, S., You, L., Chen, D., Li, Y., and Zheng, J. (2019). Unified Strength Model of Asphalt Mixture under Various Loading Modes. Materials 12, 889. doi:10.3390/ma12060889

Xie, J., and Wang, Y. (2019). Comparative Study on Torsional Shear and Triaxial Test of Asphalt Mixtures. Adv. Civil Eng. 2019, 1-8. doi:10.1155/2019/1856298

Xu, Y. J. (1994). Calendar. Mech. Eng. 8, 62-63. doi:10.6052/1000-0992-1994-121

Xue, F. L. (1997). The Comparison of the Value on the Tresca and Mises the Yielding Theory. Mech. Eng. 5, 75. doi:10.6052/1000-0992-1997-154

Yang, Q., Chen, L., Wang, P., and Dai, J. (2015). New Asphalt Pavement Failure Criterion Based on Unified Strength Theory. J. Wuhan Univ. Technol.-Mat. Sci. Edit. 30, 528-532. doi:10.1007/s11595-015-1184-8

Yu, M.-h. (2002). Advances in Strength Theories for Materials under Complex Stress State in the 20th century. Appl. Mech. Rev. Assess. World Lit. Eng. Sci. 55, 169-218. doi:10.1115/1.1472455

Yu, M.-H., Kolupaev, V. A., Li, Y.-M., and Li, J.-C. (2011). Advances in Unified Strength Theory and its Generalization. Proced. Eng. 10, 2508-2513. doi:10.1016/j.proeng.2011.04.413

Yu, M. H. (1992). A New Model and Theory on Yield and Failure of Materials under the Complex Stress State. Mech. Behav. Mater. VI 3 841-846. doi:10.1016/B978-0-08-037890-9.50389-6

Yu, M. H. (2018) Unified Strength Theory and Its Applications[M]. Singapore. Springer, 40-68. doi:10.1007/978-981-10-6247-6

Yu, M. H. (1994). Unified Strength Theory for Geomaterials and Its Applications. Chin. J. Geotechnical Eng. 2, 1-10.

Zhang, Y., and Li, L. H. (2012). Investigation of Asphalt Mixture Co-axle Shear Strength Test Method. J. Tongji Univ. 8, 1180-1184. doi:10.3969/j.issn.0253374x.2012.08.010

Conflict of Interest: The authors declare that the research was conducted in the absence of any commercial or financial relationships that could be construed as a potential conflict of interest.

Publisher's Note: All claims expressed in this article are solely those of the authors and do not necessarily represent those of their affiliated organizations, or those of the publisher, the editors and the reviewers. Any product that may be evaluated in this article, or claim that may be made by its manufacturer, is not guaranteed or endorsed by the publisher.

Copyright (๐ 2021 Qian, Yang, Li, Yu, Gong and Zhou. This is an open-access article distributed under the terms of the Creative Commons Attribution License (CC BY). The use, distribution or reproduction in other forums is permitted, provided the original author(s) and the copyright owner(s) are credited and that the original publication in this journal is cited, in accordance with accepted academic practice. No use, distribution or reproduction is permitted which does not comply with these terms. 